\title{
Modeling the Survival of Tuberculosis Patients in Eastern Zone of Tigray Regional State
}

This article was published in the following Dove Press journal:

Risk Management and Healthcare Policy

Mulugeta Geremew Geleso (D)

Department of Statistics, Wolkite University, Wolkite, Ethiopia
Correspondence: Mulugeta Geremew Geleso

Tel +25I-91373I672

Email mulerger@gmail.com
Background: Tuberculosis (TB) is still a public health problem and amongst the top ten leading causes of death. The aim of this paper was to identify the factors that significantly affect the survival of tuberculosis patients.

Methods: A retrospective cohort study was carried out in Adigrat General and Wukro hospitals, Eastern Zone of Tigray region, Ethiopia. Data for this study were obtained from medical records of all TB cases registered from September 2016 to August 2017 in the two hospitals. Log-rank test and Kaplan-Meier plot were used to evaluate the survival pattern of TB patients. A multivariable Cox proportional regression model was employed to identify the predictors of mortality. Factors with a $P$-value smaller than 0.05 were taken as statistically significant facilitators of TB death.

Results: Of the 397 patients studied over the specified period, 23 (5.8\%) had died. A statistically significant survival difference was observed among gender, residence, HIV status, treatment category, and age category of patients. In multivariable cox regression, lower survival rates were observed among patients aged $\geq 45$ years $(\mathrm{HR}=5.315,95 \% \mathrm{CI}$ : 1.231-22.959), relapse cases ( $\mathrm{HR}=4.069,95 \% \mathrm{CI}: 1.636-10.119)$, patients with extrapulmonary TB $(\mathrm{HR}=3.054,95 \% \mathrm{CI}: 1.044-8.940)$, patients from rural areas $(\mathrm{HR}=2.834,95 \%$ CI: 1.161-6.916), patients with a bodyweight of $\leq 50 \mathrm{~kg}$ and HIV-positive patients.

Conclusion: Based on the survival experience of TB patients, advancing age, extrapulmonary TB infection, living in rural residence, lower bodyweight at beginning of treatment, HIV coinfection, and being a retreatment patient were predictors of mortality. To achieve the "End TB Strategy" goal of zero death, proper targeting of care to these vulnerable groups should be advised.

Keywords: hazard probability, mortality, tuberculosis, survival

\section{Background}

Tuberculosis (TB) is still a public health problem and amongst the top ten leading causes of death. About 1.3 million people died due to TB and an additional 0.4 million people died due to TB among HIV-positive patients in 2017. In the same year, an estimated 10 million people developed TB, among them 0.92 million people were HIV-positive. ${ }^{1}$ A new program known as the "End TB Strategy" was adopted by WHO which targets to reduce TB mortality by $95 \%$ by the end of 2035 . To attain this goal, the number of individuals who die of TB in the year 2025 should decline to $6.5 \% .^{2}$ The TB incidence rate has fallen since 2000 . Worldwide, the number of TB deaths among HIV-negative people has dropped by $29 \%$ since 2000 , from 1.8 million in 2000 to 1.3 million in 2017, and by 5\% since 2015 . The number of TB deaths among HIV-positive people has dropped by $44 \%$ since 2000 , from 
0.534 million in 2000 to 0.3 million in 2017 , and by $20 \%$ since 2015 (the baseline year of the End TB Strategy). Morbidity and mortality of TB have declined meaningfully in several parts of the developed world in recent years, but unsatisfactory achievement has been noted in other countries. A key obstacle in this respect is the absence of political decisions. $^{3}$

Ethiopia started a standardized TB prevention and control program that implements the WHO-suggested DOTS strategy in $1992 .{ }^{4}$ According to the WHO report, ${ }^{1}$ Ethiopia is among the 30 high TB burden countries with incidence rate $164 / 100,000$ and 5.2 per 100,000 cases were notified for MDR TB. According to this report, TB mortality (excluding causes of death from HIV+TB) rate is projected at 24 per 100,000 population.

Improving case notification of $\mathrm{TB}$ is required in order to provide reliable data for direct measurement of TB incidence and mortality. ${ }^{1}$ About $39 \%$ of estimated cases of TB in Ethiopia are missed; either not detected, treated, or reported to NTB. Those unnotified cases remain infectious and could be the reason for the transmission of TB within the community. ${ }^{5}$

Identifying the risk factors for TB mortality is vital for predictive purposes, but also for proper targeting of highly susceptible groups. ${ }^{6}$ To identify the causes of mortality and to make effective interventions to reduce mortality rates, studying the survival of $\mathrm{TB}$ patients will be essential. ${ }^{7}$ A number of risk factors including the age of the patient, gender, HIV status, MDR, disease severity were facilitators of death due to TB. ${ }^{8,9}$ Several studies have associated TB-HIV coinfection as a significant predictor of TB mortality. In contradiction to these findings, a study in Saudi Arabia reported an insignificant association between TB-HIV coinfection and TB mortality, which is also explained by the low TB-HIV mortality rate $(0.06 /$ 100,000 people). ${ }^{10}$

The causes of mortality are different across studies; therefore, to improve the survival experience of TB patients, investigating the facilitators of mortality due to TB in the local setting is critical. The aim of this paper was to identify the factors that significantly affect the survival of tuberculosis patients.

\section{Methods}

\section{Study Design, Area, and Period}

A retrospective cohort study was carried out to identify the factors that affect the survival of TB patients on DOTS in
Adigrat General and Wukro hospitals, Eastern Zone, Tigray region, Ethiopia from September 2016 to August 2017. Adigrat General Hospital is located in Adigrat, the administrative town of Eastern Zone. This town has a total population of 57,588 , of whom 26,010 are men and 31,578 are women. Wukro Hospital is located in Wukro town, Eastern Zone, Tigray Regional state. This town has a total population of 30,210 , of whom 14,056 are men and 15,154 are women. ${ }^{11}$

\section{Study Population}

Data for this study were obtained from medical records of all TB cases registered from September 2016 to August 2017 in the two hospitals.

\section{Data Collection and Study Variables}

The data were collected by physicians who are working at the two hospitals after undergoing training regarding the data collection. TB patients' demographic and clinical data (including age, gender, residence, baseline weight, history of previous treatment, treatment center, HIV status, and type of TB) were extracted from medical forms. The dependent variable was survival time, which was measured in months from the date treatment started to the date of death or the latter attendance to the health facility. If the patient terminated the treatment by heal or complete treatment, unsuccessful treatment, or loss to reexamination (follow-up) considered as censored.

\section{Diagnosis of Tuberculosis}

Diagnosis of pulmonary TB in the two hospitals was done based on the national algorithm; for any patient with signs and symptoms, specimens for bacteriologic examination were requested and examined with X-ray and the diagnostic method GenXpert MTB/RIF. In addition, new specimens were referred to culture when necessary. Diagnosis of extrapulmonary TB was mainly achieved by pathologic techniques and diagnostic methods including GenXpert and TB culture. ${ }^{4}$

\section{Eligibility Criteria}

All TB patients with complete medical records (irrespective of gender and age, HIV status, and type of TB) who registered in the hospitals from September 2016 to August 2017 were included.

TB patients whose medical record with missing values on the variables of interest, gender, age, HIV status, and type of TB were excluded from the study (Figure 1). 


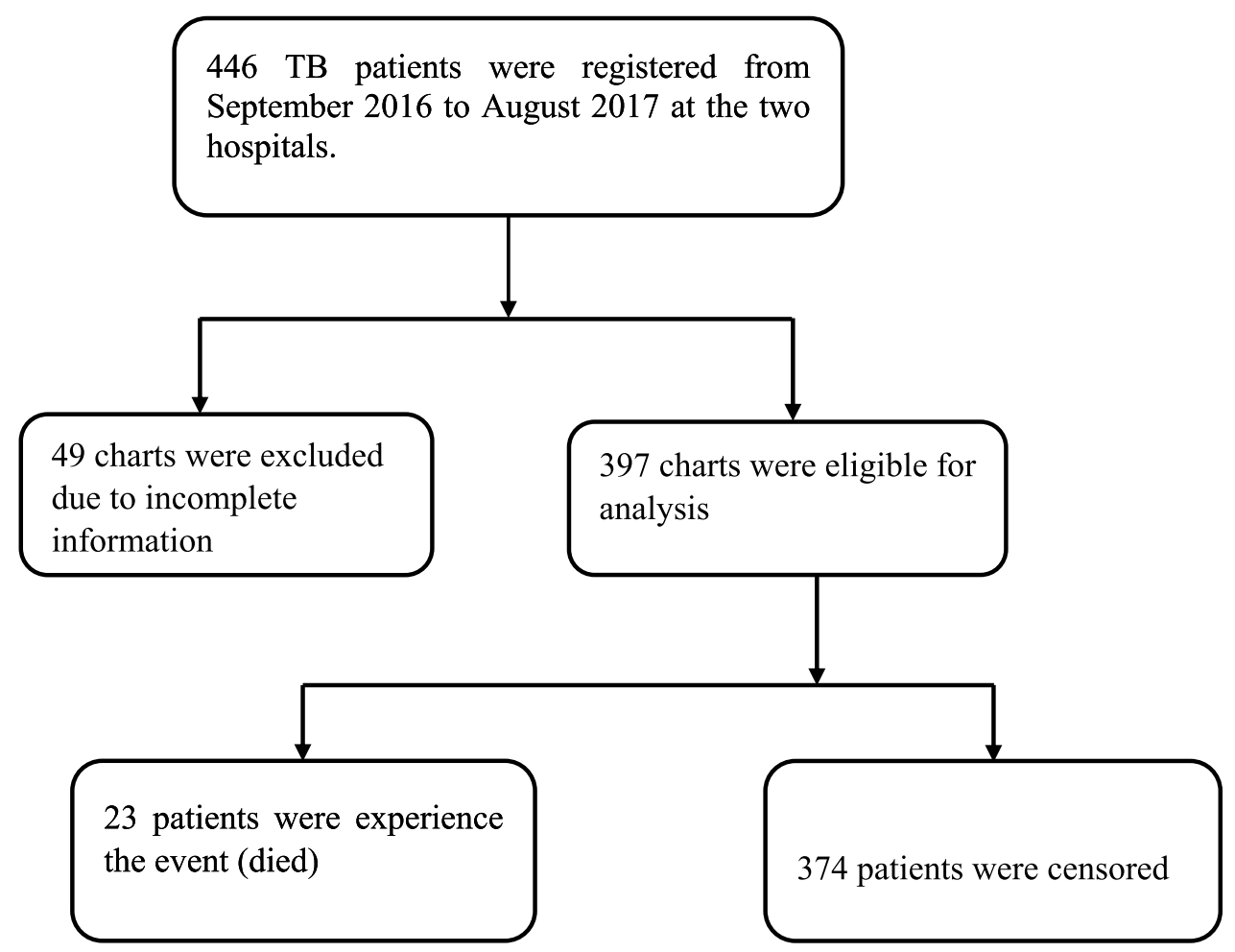

Figure I Flow chart showing the selection of Tuberculosis patients at Adigrat general and Wukro hospitals in Eastern Zone, Tigray region, Ethiopia, September 20I6August 2017.

\section{Statistical Analysis}

SPSS version 22 was used for data analysis. Log-rank test and Kaplan-Meier plot were used to evaluate the survival pattern of TB patients. A multivariable Cox proportional regression model was employed to identify the predictors of mortality using the default enter procedure in SPSS. Factors with a $P$-value smaller than 0.05 were considered statistically significant facilitators of TB death. AIC was used to compare the two candidate models (null and full), and the full model which had the smallest AIC was selected. The adequacy of the fitted model was assessed using the concordance statistic ${ }^{12}(\mathrm{c}$-statistic $=0.894)$, which shows the model had a good predictive ability.

\section{Cox Regression Model}

The Cox regression model was proposed by $\mathrm{Cox}^{13}$ for the analysis of censored survival data. The model has the following form:

$$
h(t)=\log h_{o}(t)=\beta_{1} X_{1 i}+\beta_{1} X_{2 i}+\ldots+\beta_{1} X_{k i}
$$

where $t$ is the survival time; $h_{o}(t)$ is the hazard function, determined by a set of $k$ independent variables $X_{1 i}, X_{2 i}, \ldots X_{k i}$ for $\beta_{1}, \beta_{2}, \ldots \beta_{k}$ subjects; are coefficients of the independent variables; is the baseline hazard. It corresponds to the value of the hazard if all the 's are equal to zero.

\section{Ethical Consideration}

A letter of ethical clearance was received from the research ethical clearance committee of Adigrat University. Permission letters were obtained from both Adigrat General and Wukro hospitals. The study utilized existing admission information and patient histories, therefore no informed consent was required. All the patients' data obtained from records were de-identified in accordance with data protection regulations and the declaration of Helsinki.

\section{Results}

Based on the retrospective cohort study of 397 TB patients studied over the specified period, 225 (56.7\%) were male and $172(43.3 \%)$ of the patients were female, $353(88.9 \%)$ were new TB cases, the remaining 44 (11.1\%) were relapse cases. The numbers of HIV positive and negative patients were 106 (26.7\%) and 291 (73.3\%), respectively. About $71.3 \%$ of the patients had pulmonary TB, while $28.7 \%$ were diagnosed with extrapulmonary TB. Overall, the mortality rate was $23(5.8 \%)$, whilst $374(94.2 \%)$ of the patients were censored (Table 1). 
Table I Characteristics of TB Patients and the Log-Rank Test of Predictors for Survival Time in Eastern Zone of Tigray Region, Ethiopia, September 2016-August 2017

\begin{tabular}{|c|c|c|c|c|c|c|}
\hline \multicolumn{2}{|l|}{ Variables } & \multirow{3}{*}{$\begin{array}{l}\text { Total (n=397) } \\
\mathrm{n}(\%)\end{array}$} & \multicolumn{2}{|c|}{ Survival Status at I 2 Months } & \multirow{2}{*}{\multicolumn{2}{|c|}{ Log Rank Test }} \\
\hline & & & \multirow{2}{*}{$\begin{array}{l}\text { Censored }(n=374) \\
n(\%)\end{array}$} & \multirow{2}{*}{$\begin{array}{l}\text { Died }(n=23) \\
n(\%)\end{array}$} & & \\
\hline & & & & & Chi-Square & $P$-value \\
\hline Health facility & $\begin{array}{l}\text { Adigrat General } \\
\text { Wukro }\end{array}$ & $\begin{array}{l}226(56.9) \\
|7|(43.1)\end{array}$ & $\begin{array}{l}213(94.3) \\
161(94.2)\end{array}$ & $\begin{array}{l}13(5.8) \\
10(5.9)\end{array}$ & 0.008 & 0.931 \\
\hline Gender & $\begin{array}{l}\text { Male } \\
\text { Female }\end{array}$ & $\begin{array}{l}225(56.7) \\
172(43.3)\end{array}$ & $\begin{array}{l}217(96.4) \\
157(91.3)\end{array}$ & $\begin{array}{l}8(3.6) \\
15(8.7)\end{array}$ & 4.774 & 0.029 \\
\hline Residence & $\begin{array}{l}\text { Urban } \\
\text { Rural }\end{array}$ & $\begin{array}{l}23 \mid(58.2) \\
\mid 66(4 \mid .8)\end{array}$ & $\begin{array}{l}223(96.5) \\
|5|(9 \mid .0)\end{array}$ & $\begin{array}{l}8(3.5) \\
15(9.0)\end{array}$ & 5.59 & 0.018 \\
\hline Type of TB & $\begin{array}{l}\text { P/Positive } \\
\text { P/Negative } \\
\text { EP }\end{array}$ & $\begin{array}{l}159(40.1) \\
124(31.2) \\
114(28.7)\end{array}$ & $\begin{array}{l}150(94.3) \\
120(96.8) \\
104(9 \mid .2)\end{array}$ & $\begin{array}{l}9(5.7) \\
4(3.2) \\
10(8.8)\end{array}$ & 3.296 & 0.192 \\
\hline HIV status & $\begin{array}{l}\text { Positive } \\
\text { Negative }\end{array}$ & $\begin{array}{l}106(26.7) \\
291(73.3)\end{array}$ & $\begin{array}{l}90(84.9) \\
284(97.6)\end{array}$ & $\begin{array}{l}16(15.1) \\
7(2.4)\end{array}$ & 23.376 & $<0.001$ \\
\hline Treatment category & $\begin{array}{l}\text { New } \\
\text { Relapsed }\end{array}$ & $\begin{array}{l}353 \text { (88.9) } \\
44 \text { (II.I) }\end{array}$ & $\begin{array}{l}34 I(96.6) \\
33(75.0)\end{array}$ & $\begin{array}{l}\text { I2(3.4) } \\
\text { II (25.0) }\end{array}$ & 35.833 & $<0.001$ \\
\hline Age group & $\begin{array}{l}<24 \\
25-44 \\
\geq 45\end{array}$ & $\begin{array}{l}144(36.3) \\
185(46.6) \\
68(17.1)\end{array}$ & $\begin{array}{l}|4|(97.9) \\
\mid 77(95.7) \\
56(82.4)\end{array}$ & $\begin{array}{l}3(2.1) \\
8(4.3) \\
12(17.7)\end{array}$ & 22.520 & $<0.001$ \\
\hline Baseline weight & $\begin{array}{l}\leq 50 \\
>50\end{array}$ & $\begin{array}{l}182(45.8) \\
215(54.2)\end{array}$ & $\begin{array}{l}168(92.3) \\
206(98.8)\end{array}$ & $\begin{array}{l}14(7.7) \\
9(4.2)\end{array}$ & 2.093 & 0.148 \\
\hline
\end{tabular}

Note: Values are presented as numbers and percentages (\%).

Abbreviations: EP, extrapulmonary; HIV, human immunodeficiency virus; P/Positive, pulmonary positive; P/Negative, pulmonary negative; TB, tuberculosis.

Of the 374 patients who were censored, $104(91.2 \%)$ had extrapulmonary tuberculosis, 151 (91\%) were rural residents, 157 (91.3\%) were female, 90 (84.9\%) were HIV-infected, $33(75 \%)$ were relapsed cases and 161 (94.2\%) treated at Wukro Hospital. Of the 23 TB cases who died during medication, 8 (34.8\%) were male, $15(65.2 \%)$ were from rural areas, $12(52.2 \%)$ were admitted as new patients, $16(15.1 \%)$ were HIV-positive, and $13(94.3 \%)$ were treated at Adigrat General Hospital.

The survival experiences of different groups were evaluated with the Log-rank test. It demonstrated that there is a statistically significant survival difference among gender $(P$-value $=0.029)$, residence $(P$-value $=0.018)$, HIV status ( $P$-value $<0.001)$, treatment category $(P$-value $<0.001)$ and age category of patients $(P$-value $<0.001)$ at $5 \%$ significant level (Table 1).

The Kaplan-Meier survival plots compare the survival between substratas when classified by treatment category (Figure 2A), patients who treated previously had lower survival. Based on the HIV status of TB patients, survival was lower for HIV positives (Figure 2B). When classified by age group, patients whose age was $\geq 45$ years had the lowest survival among their groups (Figure 2C). Moreover, TB patients from rural areas and females had the lowest survival among their groups (Figure 2D and E).

\section{Risk Factors for Mortality}

Cox proportional hazard regression results showed that the six factors (residence, type of TB, HIV status, treatment category, age, and bodyweight) were significant risk factors for mortality among TB patients. Health facility and gender were not predictors of TB mortality. In multivariable Cox regression, lower survival rates were observed among patients aged $\geq 45$ years $(\mathrm{HR}=5.315$, 95\% CI: $1.23-22.959)$, relapse cases $(\mathrm{HR}=4.069,95 \%$ CI: 1.636-10.119), patients with extrapulmonary TB (HR $=3.054,95 \%$ CI: $1.044-8.940)$, patients from rural areas $(\mathrm{HR}=2.834,95 \% \mathrm{CI}: 1.161-6.916)$, patients with a bodyweight of $\leq 50 \mathrm{~kg}$, and HIV-positive patients (Table 2). 

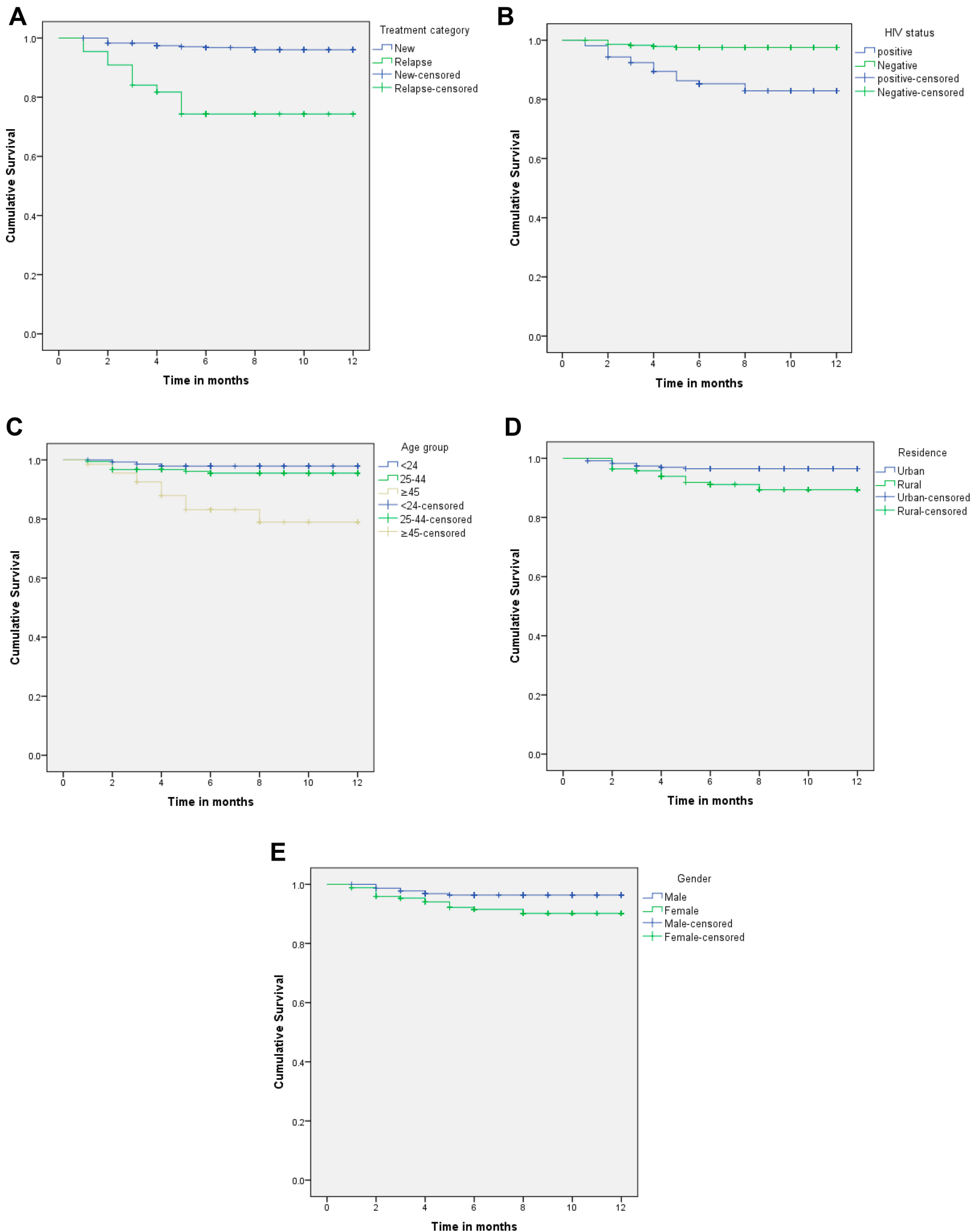

Figure 2 (A) 12-month survival curve of tuberculosis patients according to treatment category in Eastern Zone of Tigray region, Ethiopia, September 2016-August 2017. (B) 12-month survival curve of tuberculosis patients according to human immunodeficiency virus (HIV) status in Eastern Zone of Tigray region, Ethiopia, September 2016August 2017. (C) 12-month survival curve of tuberculosis patients according to age group in Eastern Zone of Tigray region, Ethiopia, September 2016-August 2017. (D) 12month survival curve of tuberculosis patients according to residence in Eastern Zone of Tigray region, Ethiopia, September 2016-August 2017. (E) 12-month survival curve of tuberculosis patients according to gender in Eastern Zone of Tigray region, Ethiopia, September 2016-August 2017. 
Table 2 Predictors of Death During TB Treatment Among Patients on DOTS Program in Eastern Zone of Tigray Region, Ethiopia, September 2016-August 2017

\begin{tabular}{|c|c|c|c|c|c|}
\hline \multirow[t]{2}{*}{ Variables } & \multirow[t]{2}{*}{ B } & \multicolumn{2}{|l|}{ Status } & \multirow[t]{2}{*}{ HR $(95 \% \mathrm{Cl})$} & \multirow[t]{2}{*}{$P$-value } \\
\hline & & Censored & Died & & \\
\hline \multicolumn{6}{|l|}{ Health facility } \\
\hline Adigrat General & - & $213(94.3)$ & $13(5.8)$ & - & \\
\hline Wukro & 0.613 & $161(94.2)$ & $10(5.9)$ & I.845 (0.68I, 4.998) & 0.228 \\
\hline \multicolumn{6}{|l|}{ Gender } \\
\hline Male & - & $217(96.4)$ & $8(3.6)$ & - & \\
\hline Female & 0.564 & I57 (9|.3) & I5 (8.7) & $1.758(0.7 \mid 4,4.326)$ & 0.219 \\
\hline \multicolumn{6}{|l|}{ Residence } \\
\hline Urban & - & $223(96.5)$ & $8(3.5)$ & & \\
\hline Rural & 1.042 & I5I (91.0) & $15(9.0)$ & $2.834(1.161,6.916)$ & 0.022 \\
\hline \multicolumn{6}{|l|}{ Type of TB } \\
\hline P/Positive & - & I $50(94.3)$ & $9(5.7)$ & - & \\
\hline P/Negative & -0.476 & $120(96.8)$ & $4(3.2)$ & $0.621(0.174,2.220)$ & 0.464 \\
\hline EP & 1.117 & $104(91.2)$ & $10(8.8)$ & $3.054(1.044,8.940)$ & 0.042 \\
\hline \multicolumn{6}{|l|}{ HIV status } \\
\hline Positive & & $90(84.9)$ & $16(15.1)$ & - & \\
\hline Negative & -1.645 & $284(97.6)$ & $7(2.4)$ & $0.193(0.066,0.565)$ & 0.003 \\
\hline \multicolumn{6}{|l|}{ Treatment category } \\
\hline New & - & 341 (96.6) & $12(3.4)$ & - & \\
\hline Relapse & 1.403 & $33(75.0)$ & II (25.0) & $4.069(1.636,10.119)$ & 0.003 \\
\hline \multicolumn{6}{|l|}{ Age group } \\
\hline$<24$ & - & |4| (97.9) & $3(2.1)$ & - & \\
\hline $25-44$ & 0.082 & I 77 (95.7) & $8(4.3)$ & $\mathrm{I} .085(0.252,4.677)$ & 0.913 \\
\hline$\geq 45$ & $1.67 \mid$ & $56(82.4)$ & $12(17.7)$ & $5.315(1.231,22.959)$ & 0.025 \\
\hline \multicolumn{6}{|l|}{ Baseline weight } \\
\hline$\leq 50$ & - & $168(92.3)$ & $14(7.7)$ & - & \\
\hline$>50$ & -1.212 & $206(98.8)$ & $9(4.2)$ & $0.298(0.11 \mathrm{I}, 0.796)$ & 0.016 \\
\hline
\end{tabular}

Notes: $(-)$ indicates the reference category, values are presented as number and percentage (\%).

Abbreviations: $\mathrm{Cl}$, confidence interval; HIV, human immunodeficiency virus; HR, hazard ratio; TB, tuberculosis; P/Positive, pulmonary positive; P/Negative, pulmonary negative.

\section{Discussion}

During the follow-up period, $5.8 \%$ of the patients died. The number of deaths in this finding was higher than the $3.9 \%$ reported from Tigray, ${ }^{14}$ but lower than from previous findings including Dessie, ${ }^{7}$ Mekelle, ${ }^{15}$ and Nigeria. ${ }^{16}$

The current study demonstrated that lower survival probability in HIV-positive patients was observed compared to HIV-negative patients. This is due to the fact that HIV patients are likely to become malnourished from constantly being sick, from diarrhea that reduces the absorption of nutrients, from loss of appetite and sores of the mouth that make eating difficult for them, and from opportunistic infections. ${ }^{17}$ The higher prevalence of MDR among TB-HIV coinfected patients may be another reason. ${ }^{10}$ In contradiction to the current finding, studies in Ethiopia, ${ }^{18}$ Saudi Arabia, ${ }^{10}$ and southern India ${ }^{19}$ showed that HIV status was not significantly associated with mortality of TB patients. The possible explanation for this observed variation might be differences in the sociodemographic characteristics of TB patients, ${ }^{8}$ the quality of service in the TB/HIV clinic; health education, proper counseling, and appropriate follow-up by the clinicians. The current finding that HIV-positive patients had a higher likelihood of experiencing death during treatment than HIV-negative TB patients is congruent with a study in Nigeria, ${ }^{20}$ which stated that TB-HIV co-infected patients 
were at the highest risk of death. Findings from Brazil ${ }^{21}$ and $\operatorname{Iran}^{22}$ revealed that the hazard of dying of TB-HIV co-infection was 1.46 and 11.9 more likely compared to HIV-negative TB patients, respectively.

Lower survival rate was observed among patients from rural areas, who had a higher risk of experiencing death. This demographic factor was associated with mortality in numerous studies. ${ }^{7,20}$ This could be due to the health structure in the least-developed nations, which suffers from a deficiency of human resources and inadequate facilities for rural residents. In contradiction to this finding, other studies reported that the place of residence was not significantly associated with death. ${ }^{15,23}$

In the present study, patients aged $\geq 45$ years (HR $=$ 5.32, 95\% CI: 1.23-22.96) had a lower survival rate as compared to the younger age groups. A wider confidence interval of hazard ratio for age was observed. A small sample size or the variation of events observed in each age category could attribute to this effect. The covariate age significantly affected the survival experience of TB patients, and getting older was the significant risk factor for death due to TB. ${ }^{6}$ A higher mortality rate was reported by Adamu et al among patients aged $\geq 45-54(30.8 \%)$ as compared with younger age groups $(9.6 \%) .{ }^{16}$ The cause of this association is that advancing age is associated with immunosenescence, which is a process that affects the entire immune system. It corresponds to multiple alterations of the immune system, which results in a higher rate of infections, an increase of comorbidities, and reduced responses to treatments. ${ }^{24}$

The current study revealed that patients with a bodyweight of more than $50 \mathrm{~kg}$ at the beginning of treatment were $70 \%$ less likely to die than patients whose bodyweight $\leq 50 \mathrm{~kg}$. This implies an adverse outcome of malnutrition on TB patient survival. Studies in northwest Ethiopia ${ }^{8}$ and southern India $^{25}$ showed that patients whose weight was $<35 \mathrm{~kg}$ at the beginning of treatment were 3.9 and 3.7 more likely to die compared to patients whose weight was more than $35 \mathrm{~kg}$, respectively. Bodyweight is an important indicator of malnutrition. Malnutrition adversely affects immune function, ${ }^{26}$ and as a result, increases comorbidity. ${ }^{24}$ Comorbidity was an important predictor of survival for patients with tuberculosis in several studies. ${ }^{27-30}$

Female TB patients had lower survival compared to male patients and this difference was statistically significant in the univariate model. However, this difference was not significant in multivariable Cox regression. Similar studies reported no significant variation in terms of mortality between male and female patients, but the proportion of death was higher in female patients. ${ }^{16,31}$

Previous studies demonstrated insignificant variation in terms of mortality between new TB patients and relapses. ${ }^{7,20,32}$ In this study previous TB treatment was considered a significant risk factor for mortality, which is in line with a study conducted in the southern region of Zimbabwe. ${ }^{9}$ Patients who were treated for TB in the past had a greater likelihood of developing MDR TB and were more likely to die than patients who were not diagnosed with TB previously. ${ }^{33}$

Concerning the relationship between the type of TB and death, only extrapulmonary TB was a significant risk factor for mortality. The likelihood of dying for patients with extrapulmonary TB was 3 times higher than for patients with pulmonary positive. Higher proportions of death among extra-pulmonary TB patients were reported in studies from Ethiopia, ${ }^{15}$ Iraq, ${ }^{34}$ and Cameron. ${ }^{35}$ This noticeable rate of mortality might be due to insufficient information about the extrapulmonary TB symptoms and the lack of access to medical facilities. A recent report from China revealed that the diagnostic breach and failing to diagnose extrapulmonary TB were high; this might be due to the disease being diagnosed from clinical symptoms. ${ }^{36}$ Extrapulmonary TB is complicated and difficult to diagnose, and it requires a high clinical diagnostic measure. ${ }^{34}$ Time until diagnosis was significantly associated with morbidity and mortality. ${ }^{37}$

\section{Limitations of the Study}

This study was done retrospectively to investigate the factors associated with mortality, and some important risk factors (like ART, CPT, and other clinical variables) were not included due to incomplete information in the patients' logbook at the health centers. Furthermore, the specific reason for death may not be known exactly.

\section{Conclusion}

Based on the survival experience of TB patients, advancing age, extrapulmonary infection, living in rural residence, lower bodyweight at beginning of treatment, HIV co-infection, and being a retreatment patient were predictors of mortality and had a negative effect on the survival time. To achieve the "End TB Strategy" goal of zero death, proper targeting of care to these vulnerable groups should be advised. 


\section{Abbreviations}

AIC, Akaike information criterion; ART, antiretroviral therapy; CI, confidence interval; CFR, case fatality ratio; CPT, cotrimoxazole prophylaxis therapy; HR, hazard ratio; HIV, human immunodeficiency virus; MDR, multidrugresistant; NTB, national tuberculosis program.

\section{Data Sharing Statement}

The raw data set used for this study is offered on reasonable request.

\section{Acknowledgments}

The author acknowledges Adigrat and Wukro hospital staff for their support throughout the data collection. I am also thankful to Adigrat University for funding this project.

\section{Disclosure}

The author declares no conflict of interest concerning this paper.

\section{References}

1. WHO. Global Tuberculosis Report 2018. Geneva: World Health Organization; 2018. doi:WHO/HTM/TB/2017.23

2. World Health Assembly. Global Strategy and Targets for Tuberculosis Prevention, Care and Control After 2015 (WHA67.1, Agenda Item 12.1). Geneva: World Health Assembly; 2015

3. Olaleye A, Beke A. Determinants of Survival of Patients with Tuberculosis in Developing Countries. In: Tuberculosis. 2018. doi: $10.5772 /$ intechopen. 75890

4. Federal Ministry of Health. Guidelines for Clinical and Programmatic Management of TB, TB/HIV and Leprosy in Ethiopia. 5th. Addis Ababa; 2012.

5. FDRE Ministry of Health. Health Sector Transformation Plan. Addis Ababa, Ethiopia; 2015.

6. Heunis JC, Kigozi NG, Chikobvu P, Botha S, Van Rensburg HD. Risk factors for mortality in TB patients: a 10-year electronic record review in a South African province. BMC Public Health. 2017;17. doi:10.1186/s12889-016-3972-2.

7. Beyene Y, Geresu B, Mulu A. Mortality among tuberculosis patients under DOTS programme: a historical cohort study. BMC Public Health. 2016;16. doi:10.1186/s12889-016-3557-0.

8. Birlie A, Tesfaw G, Dejene T, Woldemichael K. Time to death and associated factors among tuberculosis patients in dangila woreda, northwest Ethiopia. PLoS One. 2015;10:e0144244. doi:10.1371/journal. pone. 0144244

9. Takarinda KC, Sandy C, Masuka N, et al. Factors associated with mortality among patients on TB treatment in the Southern region of Zimbabwe, 2013. Tuberc Res Treat. 2017. doi:10.1155/2017/6232071

10. Aljohaney AA. Mortality of patients hospitalized for active tuberculosis in King Abdulaziz University Hospital, Jeddah, Saudi Arabia. Saudi Med J. 2018;39(3):267-272. doi:10.15537/smj.2018.3.22280

11. Central Statistical Agency. Population and Housing Census of 2007. Ethiopia; 2007.

12. Harrell FE, Lee KL, Mark DB. Multivariable prognostic models: issues in developing models, evaluating assumptions and adequacy, and measuring and reducing errors. Stat Med. 1996;15(4):361-387. doi:10.1002/ (SICI)1097-0258(19960229)15:4<361::AID-SIM168>3.0.CO;2-4
13. Cox DR. Regression models and life-tables. J R Stat Soc Ser B. 1972. doi:10.1111/j.2517-6161.1972.tb00899.x

14. Berhe G, Enquselassie F, Aseffa A. Treatment outcome of smear-positive pulmonary tuberculosis patients in Tigray Region, Northern Ethiopia. BMC Public Health. 2012;12(1). doi:10.1186/ 1471-2458-12-537

15. Asgedom SW, Tesfaye D, Nirayo YL, Atey TM. Time to death and risk factors among tuberculosis patients in Northern Ethiopia. BMC Res Notes. 2018;11. doi:10.1186/s13104-018-3806-7.

16. Adamu AL, Gadanya MA, Abubakar IS, et al. High mortality among tuberculosis patients on treatment in Nigeria: a retrospective cohort study. BMC Infect Dis. 2017;17. doi:10.1186/s12879-017-2249-4

17. Sinshaw Y, Alemu S, Fekadu A, Gizachew M. Successful TB treatment outcome and its associated factors among TB/HIV co-infected patients attending Gondar University Referral Hospital, Northwest Ethiopia: an institution based cross-sectional study. BMC Infect Dis. 2017;17. doi:10.1186/s12879-017-2238-7.

18. Shaweno D, Worku A. Tuberculosis treatment survival of HIV positive TB patients on directly observed treatment short-course in Southern Ethiopia: a retrospective cohort study. BMC Res Notes. 2012;5. doi:10.1186/1756-0500-5-682.

19. Jonnalagada $\mathrm{S}, \mathrm{AD} \mathrm{H}$, Zachariah $\mathrm{R}$, et al. The timing of death in patients with tuberculosis who die during anti-tuberculosis treatment in Andhra Pradesh, South India. BMC Public Health. 2011;11. doi:10.1186/1471-2458-11-921

20. Alobu I, Oshi SN, Oshi DC, Ukwaja KN. Risk factors of treatment default and death among tuberculosis patients in a resource-limited setting. Asian Pac J Trop Med. 2014;7:977-984. doi:10.1016/S19957645(14)60172-3

21. Gayoso R, Dalcolmo M, Braga JU, Barreira D. Predictors of mortality in multidrug-resistant tuberculosis patients from Brazilian reference centers, 2005 to 2012. Brazilian J Infect Dis. 2018;22:305-310. doi:10.1016/j.bjid.2018.07.002

22. Alavi-Naini R, Moghtaderi A, Metanat M, Mohammadi M, Zabetian M. Factors associated with mortality in tuberculosis patients. J Res Med Sci. 2013;18(1):52.

23. Woldeamanuel GG, Mingude AB. Factors associated with mortality in tuberculosis patients at Debre Birhan Referral Hospital, Ethiopia: a retrospective study. J Trop Dis. 2018;07. doi:10.4172/2329891x.1000289.

24. Montgomery RR, Shaw AC. Paradoxical changes in innate immunity in aging: recent progress and new directions. J Leukoc Biol. 2015;98:937-943. doi:10.1189/jlb.5mr0315-104r

25. Vasantha M, Gopi PG, Subramani R. Survival of tuberculosis patients treated under DOTS in a rural Tuberculosis Unit (TU), south India. Indian J Tuberc. 2008;55(2):64-69.

26. Keusch GT. Malnutrition, infection, and immune function. In: Suskind RM, Lewinter-Suskind L, editors. Nestle Nutrition Workshop Series. USA: Nestec Ltd., Vevey/Raven Press, Ltd.; 1990.

27. Oursler KK, Moore RD, Bishai WR, Harrington SM, Pope DS, Chaisson RE. Survival of patients with pulmonary tuberculosis: clinical and molecular epidemiologic factors. Clin Infect Dis. 2002; (6):752-759. doi:10.1086/338784

28. Ranzani OT, Rodrigues LC, Bombarda S, Minto CM, Waldman EA, Carvalho CRR. Long-term survival and cause-specific mortality of patients newly diagnosed with tuberculosis in São Paulo state, Brazil, 2010-15: a population-based, longitudinal study. Lancet Infect Dis. 2020;20(1):123-132. doi:10.1016/S1473-3099(19)30518-3

29. Workneh MH, Bjune GA, Yimer SA. Diabetes mellitus is associated with increased mortality during tuberculosis treatment: a prospective cohort study among tuberculosis patients in South-Eastern Amahra Region, Ethiopia. Infect Dis Poverty. 2016;5. doi:10.1186/s40249-016-0115-z.

30. Rao VK, Iademarco EP, Fraser VJ, Kollef MH. The impact of comorbidity on mortality following in-hospital diagnosis of tuberculosis. Chest. 1998;114:1244-1252. doi:10.1378/chest.114.5. 1244 
31. Chan CK, Wong KH, Lee MP, et al. Risk factors associated with 1-year mortality among patients with HIV-associated tuberculosis in areas with intermediate tuberculosis burden and low HIV prevalence. Hong Kong Med J. 2018;24(5):473-483. doi:10.12809/hkmj187303

32. Pardeshi G. Survival analysis and risk factors for death in tuberculosis patients on directly observed treatment-short course. Indian J Med Sci. 2009;63:180. doi:10.4103/0019-5359.53163

33. Tocque K, Convrey RP, Bellis MA, Beeching NJ, Davies PD. Elevated mortality following diagnosis with a treatable disease: tuberculosis. Int J Tuberc Lung Dis. 2005;9(7):797-802.

34. Balaky STJ, Mawlood AH, Shabila NP. Survival analysis of patients with tuberculosis in Erbil, Iraqi Kurdistan region. BMC Infect Dis. 2019;19. doi:10.1186/s12879-019-4544-8.
35. Djouma FN, Noubom M, Ngomba AV, Donfack H, Kouomboua PSM, Saah MAF. Determinants of death among tuberculosis patients in a semi urban diagnostic and treatment centre of Bafoussam, West Cameroon: a retrospective case-control study. Pan Afr Med J. 2015;22. doi:10.11604/pamj.2015.22.253.6576.

36. Pang Y, An J, Shu W, et al. Epidemiology of extrapulmonary tuberculosis among inpatients, China, 2008-2017. Emerg Infect Dis. 2019;25(3):457-464. doi:10.3201/eid2503.180572

37. Khazaei HA, Rezaei N, Bagheri GR, et al. Epidemiology of tuberculosis in the southeastern Iran. Eur J Epidemiol. 2005;20:879-883. doi:10.1007/s10654-005-2152-y

\section{Publish your work in this journal}

Risk Management and Healthcare Policy is an international, peerreviewed, open access journal focusing on all aspects of public health, policy, and preventative measures to promote good health and improve morbidity and mortality in the population. The journa welcomes submitted papers covering original research, basic science, clinical \& epidemiological studies, reviews and evaluations, guidelines, expert opinion and commentary, case reports and extended reports. The manuscript management system is completely online and includes a very quick and fair peer-review system, which is all easy to use. Visit http://www.dovepress.com/testimonials.php to read real quotes from published authors.

Submit your manuscript here: https://www.dovepress.com/risk-management-and-healthcare-policy-journal 